\begin{tabular}{c|c|c}
\hline \hline & CLIMATE RESEARCH & Published December 20 \\
Vol. 23: 1-9, 2002 & Clim Res & \\
\hline
\end{tabular}

\title{
Revised 21st century temperature projections
}

\author{
Patrick J. Michaels ${ }^{1,2, *}$, Paul C. Knappenberger ${ }^{3, *}$, Oliver W. Frauenfeld ${ }^{1}$, \\ Robert E. Davis ${ }^{1}$ \\ ${ }^{1}$ Department of Environmental Sciences, PO Box 400123, University of Virginia, Charlottesville, Virginia 22904-4123, USA \\ ${ }^{2}$ Cato Institute, Washington, DC 20001-5403, USA \\ ${ }^{3}$ New Hope Environmental Services, 5 Boar's Head Lane, Suite 101, Charlottesville, Virginia 22903, USA
}

\begin{abstract}
Temperature projections for the 21st century made in the Third Assessment Report (TAR) of the United Nations Intergovernmental Panel on Climate Change (IPCC) indicate a rise of 1.4 to $5.8^{\circ} \mathrm{C}$ for $1990-2100$. However, several independent lines of evidence suggest that the projections at the upper end of this range are not well supported. Since the publication of the TAR, several findings have appeared in the scientific literature that challenge many of the assumptions that generated the TAR temperature range. Incorporating new findings on the radiative forcing of black carbon (BC) aerosols, the magnitude of the climate sensitivity, and the strength of the climate/carbon cycle feedbacks into a simple upwelling diffusion/energy balance model similar to the one that was used in the TAR, we find that the range of projected warming for the $1990-2100$ period is reduced to $1.1-2.8^{\circ} \mathrm{C}$. When we adjust the TAR emissions scenarios to include an atmospheric $\mathrm{CO}_{2}$ pathway that is based upon observed $\mathrm{CO}_{2}$ increases during the past $25 \mathrm{yr}$, we find a warming range of $1.5-2.6^{\circ} \mathrm{C}$ prior to the adjustments for the new findings. Factoring in these findings along with the adjusted $\mathrm{CO}_{2}$ pathway reduces the range to $1.0-1.6^{\circ} \mathrm{C}$. And thirdly, a simple empirical adjustment to the average of a large family of models, based upon observed changes in temperature, yields a warming range of $1.3-3.0^{\circ} \mathrm{C}$, with a central value of $1.9^{\circ} \mathrm{C}$. The constancy of these somewhat independent results encourages us to conclude that 21st century warming will be modest and near the low end of the IPCC TAR projections.
\end{abstract}

KEY WORDS: Temperature projections - Climate change - Global warming - Climate models · Impact assessment

Resale or republication not permitted without written consent of the publisher

\section{INTRODUCTION}

Much has been made of 21st century temperature projections from the Third Assessment Report (TAR) of the United Nations Intergovernmental Panel on Climate Change (IPCC) that indicate a rise of 1.4 to $5.8^{\circ} \mathrm{C}$ during the 1990-2100 period. The projections are based upon a number of 'storylines' describing what the IPCC believes are self-consistent social development possibilities for the next $100 \mathrm{yr}$. These are factored into what are known as 'SRES' scenarios, as they were published in an IPCC document known as the 'Special Report on Emissions' (IPCC 2000). These 'storylines' range from high population growth/high emission assumptions to low population growth with substantial substitution of low greenhouse gas technologies such as wind, solar and nuclear.

This report re-examines the IPCC TAR range of 21st century temperature projections using 3 methods. The first adjusts the sensitivity of the thermal response to changes in atmospheric $\mathrm{CO}_{2}$ based upon recent findings which imply that this sensitivity is less than previously assumed, and the second adjusts the SRES-projected changes in $\mathrm{CO}_{2}$ using the actual trends established in the last quarter-century. The third adjusts the average slope of a large collection of General Circulation Models (GCMs) for observed increases in temperature during the recent warming of the past $25 \mathrm{yr}$. 


\section{ADJUSTMENT IN RADIATIVE FORCING, THERMAL SENSITIVITY, AND CLIMATE/CARBON CYCLE FEEDBACK}

We used the 'Model for the Assessment of Greenhouse-gas Induced Climate Change' (MAGICC), a simple upwelling diffusion/energy balance (UD/EB) model (Wigley \& Raper 1987, Raper et al. 1996), as the tool to investigate the effects of altering the climate parameters and emissions scenarios on average global temperatures for the next $100 \mathrm{yr}$. MAGICC takes as input trace gas emission scenarios (such as the ones from the TAR SRES) and outputs global average temperature for user-defined time steps. The use of a simple UD/EB model to emulate global-scale temperature results of fully integrated Atmosphere-Ocean General Circulation Models (A/OGCMs) has been a standard practice employed by the IPCC in order to simulate the effects of many different model parameter and emissions scenario combinations without the cost (both physical and temporal) of running full A/OGCMs.

The version of MAGICC that we used was extensively used by the IPCC in its Second Assessment Report (SAR) (IPCC 1996). We were not able to obtain the updated version employed by the IPCC in its TAR (IPCC 2001), despite repeated attempts to do so from its authors. The model used in the TAR produces higher temperatures for similar trace gas emissions than the SAR version because of the inclusion of a sea ice parameter, a shallower ocean mixed-layer, a climate/carbon cycle feedback, and several other minor modifications (Raper et al. 2001, IPCC 2001). Since the SAR version of MAGICC has only a limited set of userconfigurable climate parameters, it is impossible to replicate the workings of the TAR version exactly; therefore, we had to work within the limitations of the software to produce output that best emulates the TAR results.

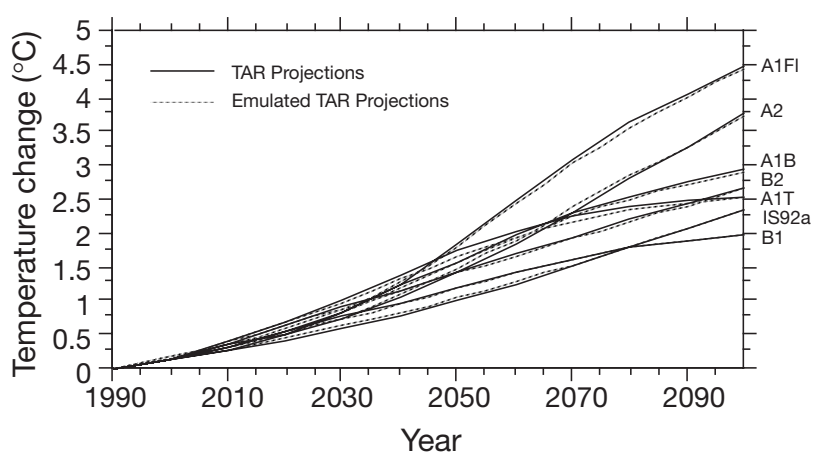

Fig. 1. Temperature projections for the 6 illustrative SRES scenarios and the IS92a scenario from the IPCC Third Assessment Report (TAR) (solid lines) and emulation of these scenarios using the SAR version of MAGICC (dotted lines)
The inclusion in TAR of a climate/carbon cycle feedback results in higher atmospheric $\mathrm{CO}_{2}$ concentrations for a particular emissions scenario than when the climate feedback is not included. An important cause of the elevated $\mathrm{CO}_{2}$ concentrations is enhanced soil respiration from elevated temperatures (IPCC 2001). To reproduce the enhanced $\mathrm{CO}_{2}$ concentrations in the version of MAGICC we employed, we increased the $\mathrm{CO}_{2}$ emissions at each time step (every $10 \mathrm{yr}$ ) within each of the 6 SRES illustrative scenarios (IPCC 2001) until we were able to closely match the $\mathrm{CO}_{2}$ concentration curves given by Wigley (2000), which are the concentration profiles used in the TAR. However, this change alone was not enough to replicate the higher temperatures resulting from the MAGICC model differences. Therefore, we altered the climate sensitivity so that for a given input emission scenario (adjusted to account for the enhanced $\mathrm{CO}_{2}$ concentrations produced by the $\mathrm{CO}_{2}$ /climate feedback), the output temperature change for the year 2100 best matched the TAR values. In every case, we had to increase the climate sensitivity. Fig. 1 shows the comparison of the average temperature projections for 6 SRES illustrative scenarios as well as the IS92a scenario (the 'central' emissions scenario from SAR) as depicted in the TAR with the projected temperatures calculated by the SAR version of MAGICC with adjusted climate sensitivities. The close correspondence (the temperature projections never differ by more than $0.1^{\circ} \mathrm{C}$, and typically the differences are less than $0.05^{\circ} \mathrm{C}$ ) indicates that our adjustment procedures allow us to very closely emulate the TAR results. Although we cannot be sure that this close emulation will continue when model parameters are subsequently altered, our experience with the model indicates that it is well behaved under a wide range of parameter settings and the alterations that we make fall within the range of values that MAGICC has been developed to incorporate.

The range of warming estimated in the TAR from the full set of 35 SRES scenarios and the MAGICC emulation of $7 \mathrm{GCMs}$ is 1.4 to $5.8^{\circ} \mathrm{C}$ by the year 2100 . The range of the average projected warming from the 7 GCMs using the 6 illustrative SRES scenarios is 2.0 to $4.5^{\circ} \mathrm{C}$ (Fig. 1). To assess how these projections may change based upon alternative determinations of climate sensitivity and future emission scenarios, we adjusted the inputs and parameters of the MAGICC model to account for the following: (1) the finding of Jacobson (2001) that the direct warming effect of black carbon (BC) aerosols (soot) is on the order of $0.55 \mathrm{~W} \mathrm{~m}^{-2}$, a value greater than that used in the TAR projections; (2) the reduction of the estimate of climate sensitivity to doubled $\mathrm{CO}_{2}$ as calculated by Lindzen et al. (2001); (3) adjustment of the positive feedback 
between global temperatures and emissions of $\mathrm{CO}_{2}$ based upon the findings of Luo et al. (2001).

By focusing on only these 3 aspects of climate change, we are not implying that other climate and climate model parameters are better constrained. In fact, many are not. For instance, the level of uncertainty of the effects of other forcing agents, such as sulfate aerosols, far exceeds that of $\mathrm{BC}$, at least within the framework of current determinations of these uncertainty levels (IPCC 2001). Our work is not intended as an exhaustive sensitivity analysis of the uncertainties of climate and climate modeling, but instead we examine the effect of refinements to the understanding of several key parameters-refinements that have occurred since the release of the TAR, and that have significant impacts on the TAR findings.

\subsection{Adjustment to the radiative forcing due to the effects of black carbon aerosol}

Jacobson (2001) determined that the global mean direct radiative forcing from $\mathrm{BC}$ aerosols was greater than any previous estimates, including the mean value used in the TAR models $\left(0.55 \mathrm{vs} 0.40 \mathrm{~W} \mathrm{~m}^{-2}\right)$. There are 2 primary anthropogenic sources of $\mathrm{BC}$ aerosols of roughly equivalent importance: incomplete combustion of fossil fuels and biomass burning. While BC emissions pathways are not explicitly defined in the SRES scenarios, the assumption used in TAR MAGICC is that the fossil fuels contribution to the total BC emissions is scaled linearly with sulfur dioxide emissions while the biomass burning component is scaled with gross deforestation (IPCC 2001). For the case of fossil fuel burning, the direct effect of $\mathrm{BC}$ emissions can be combined with the direct effect of the emissions of organic carbon (OC) and sulfate aerosols to create an 'effective' direct sulfate forcing-a user-configurable value in MAGICC. The 1990 reference value used in TAR for this sum is $-0.3 \mathrm{~W} \mathrm{~m}^{-2}$, (-0.4 from sulfate, -0.1 from $\mathrm{OC}$, and +0.2 from $\mathrm{BC}$ ). If we apply the TAR assumption that the forcing from $\mathrm{BC}$ is equally split between biomass and fossil fuel sources, then the TAR value of $+0.2 \mathrm{~W} \mathrm{~m}^{-2}$ should be increased to +0.275 in accordance with the results of Jacobson (2001), bringing the 1990 reference effective sulfate forcing value to $-0.225 \mathrm{~W} \mathrm{~m}^{-2}$. This adjustment was explicitly made in the version of MAGICC used here.

There are no user-adjustable parameters for biomass burning in the SAR version of MAGICC. In half of the 6 SRES illustrative scenarios, there is little change over time in the amount of global deforestation, while in the other half, total deforestation declines about 5 to $30 \%$ by the year 2100 . The TAR 1990 reference value for the combined direct effect of $\mathrm{BC}$ and $\mathrm{OC}$ aerosols as a result of biomass burning is $-0.2 \mathrm{~W} \mathrm{~m}^{-2}$ ( -0.4 from OC aerosols, +0.2 from $\mathrm{BC}$ aerosols). Using the results of Jacobson (2001) would increase the total forcing to $-0.125 \mathrm{~W} \mathrm{~m}^{-2}(-0.4+0.275)$. This number declines to $-0.092 \mathrm{~W} \mathrm{~m}^{-2}$ (a change of only 0.033 ) for a $30 \%$ decline in deforestation. We will consider this change to be of negligible climate consequence and ignore the impact of Jacobson (2001) on this half of the BC aerosol equation.

\subsection{Adjustment to the climate sensitivity resulting from the iris effect}

Lindzen et al. (2001) demonstrated evidence for an 'adaptive infrared iris' that acts as a negative feedback to control global temperature fluctuations. Through examinations of cloud observations made by the Japanese Geostationary Meteorological Satellite-5 over parts of the western Pacific, Lindzen et al. (2001) determined that the relative proportion of cirrus-tocumulus cloud coverage varied with the sea surface temperature (SST). Higher SSTs resulted in fewer cirrus clouds while lower SSTs were associated with a greater proportion of cirrus clouds. Since cirrus clouds have a net positive radiative forcing, this results in a negative feedback in that fewer cirrus clouds allow more infrared radiation to escape from the warmer surface, which subsequently cools, leading to an increase in the cirrus coverage and a closing of the atmospheric infrared window. Lindzen et al. (2001) find that this negative feedback, if applicable throughout the tropics, would have a magnitude that would be nearly equivalent, but of opposite sign, to the magnitude of the sum of all other positive feedbacks present in the current generation of climate models. Lindzen et al. (2001) go on to calculate that the iris effect would lower the climate sensitivity in current GCMs by about $60 \%$. Several subsequent studies (Fu et al. 2001, 2002, Harrison 2002, Hartmann \& Michelsen 2002, Lin et al. 2002) have challenged the Lindzen et al. (2001) results; however, in careful comments to these challenges (Chou et al. 2002a,b,c, Chou \& Lindzen 2002, Bell et al. 2002, Lindzen et al. 2002) the results of Lindzen et al. (2001) have been confirmed. In the series of responses to the critiques, it has been suggested that the effect of the iris on the global temperature sensitivity was initially overestimated by perhaps 15 to $20 \%$. Thus, in accordance with these new results, we will take the reduction of the values of temperature sensitivity used by current generation GCMs to be $50 \%$ - a value about $17 \%$ less than that originally proposed by Lindzen et al. (2001).

While this may seem as a rather large reduction of the current manifestations of climate sensitivity as gen- 
erated by climate models, it arises from the possibility that current climate models do not handle tropical cloud and moisture processes adequately. Lindzen et al. (2001) found that in a small sampling of climate model simulations forced by observed SSTs the observed iris effect was not present. Additionally, results consistent with the adaptive infrared iris mechanism have been recently reported by Chen et al. (2002), Wielicki et al. (2002) and Wang et al. (2002) when analyzing trends in longwave and shortwave radiation in the tropics from data collected by the satellite-borne instrumentation of a series of experiments designed to study the earth's radiation balance including the second Stratospheric Aerosol and Gas Experiment (SAGE II), the Earth Radiation Budget Experiment (ERBE), and the Clouds and the Earth's Radiant Energy System (CERES). These researchers found positive trends in outgoing longwave radiation and negative trends in reflected shortwave radiation from the mid-1980s to the late 1990s. A redistribution of the tropical cloudiness and moisture, including decreasing high level clouds and humidity and increasing low level clouds, has been identified as contributing to the observed trends. Furthermore, Wielicki et al. (2002) found that a suite of current climate models were unable to reproduce the observed data, even when forced with the observed SSTs, indicating a potential problem with the cloud response to SST forcing in the models, as implied by Linzden et al. (2001). Harvey (2000), using a simple energy balance climate model, showed that a downward vertical moisture redistribution in the tropics could lead to a decrease in the temperature sensitivity of about $15 \%$ - an effect not replicated by more complex climate models and one that is independent of actual cloud properties. Gaffen et al. (2000) report that temperature trends derived from data collected by microwave sounding units show that the temperatures in the lower troposphere in the tropics have declined since 1979 while temperature data collected from surface-based instruments show a warming trend during the same period. Independent data from radiosonde observations confirm these trend differences. These disparate temperature trends have led to an increase in the vertical lapse rate in the tropics, a behavior not captured by the 3 climate models that were examined (Gaffen et al. 2000). Hegerl \& Wallace (2002) further confirm that the temperature trends from the lower troposphere are less positive than those from the surface since the late 1970s, and for the period 1964-1981 this trend differential was reversed. They were unable to replicate the observed behavior using the most recent version of the Max Planck Institute for Meteorology climate model in either a control or a transient run and suggest that this deficiency is not limited to this model alone.
These results confirm that current climate models are not accurately capturing the cloud and moisture processes active in the tropics - processes which play a critical role in the earth's temperature sensitivity. Furthermore, these model inaccuracies result in an overestimation of the true climate sensitivity.

\subsection{Adjustment to the climate/carbon cycle feedback}

The results of Luo et al. (2001) challenged the generally accepted notion that there exists a strong positive feedback between average global temperature and average biospheric respiration, primarily the amount of $\mathrm{CO}_{2}$ released from the soil. They found that in tall grass prairie plots in the central United States, there was no elevation in soil respiration with an elevation in temperature. These results are supported by other long-term field studies (Verville et al. 1998, Liski et al. 1999). Since IPCC TAR incorporates a climate change/ $\mathrm{CO}_{2}$ feedback that includes a positive feedback between temperature and soil respiration (which IPCC SAR did not consider), the results of Luo et al. (2001) imply that the $\mathrm{CO}_{2}$ emissions pathways in TAR are overestimated.

Soil respiration is not the only factor involved in the temperature/biospheric feedback loop, although it is a major factor (Cox et al. 2000, Luo et al. 2001). In MAGICC, the effect of incorporating a climate $/ \mathrm{CO}_{2}$ feedback is an increase of atmospheric $\mathrm{CO}_{2}$ of about $4 \%$ by 2100 over the non-climate $/ \mathrm{CO}_{2}$ feedback version (the exact value depends on the particular SRES scenario). Therefore, we simulate the impact of the findings of Luo et al. (2001) by reducing the total climate $/ \mathrm{CO}_{2}$ positive feedback by $75 \%$, an amount that allows for the continued possibility of a small positive feedback from soil respiration or other terrestrial and oceanic processes. We implement this reduction by developing a $\mathrm{CO}_{2}$ emissions pathway that results in only a $1 \%$ increase in atmospheric $\mathrm{CO}_{2}$ levels rather than the $4 \%$ that would be required to achieve a match between the SAR and the TAR emissions pathways in MAGICC (as described earlier in this section).

\subsection{Results from adjustments to the radiative forcing, thermal sensitivity and climate/carbon cycle feedback}

The results from running the 6 SRES illustrative scenarios and the IS92a scenario with the adjustments for the new determinations of the radiative forcing of $\mathrm{BC}$ aerosol, the temperature sensitivity, and the climate/ $\mathrm{CO}_{2}$ feedback are shown in Fig. 2. The range of projected warming for these scenarios drops from $2.0-4.5^{\circ} \mathrm{C}$ in the TAR to $1.1-2.8^{\circ} \mathrm{C}$. As an example of 


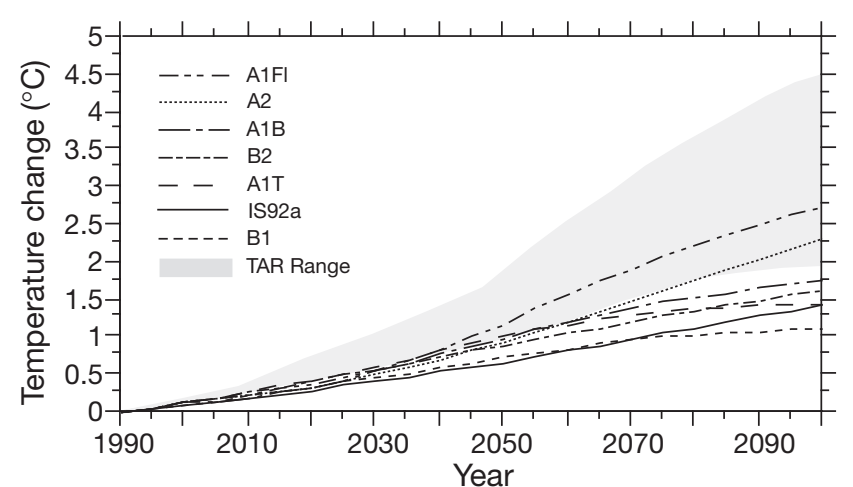

Fig. 2. 6 illustrative SRES scenarios and the IS92a scenario adjusted for an enhanced black carbon forcing (Jacobson 2001), a reduced temperature sensitivity (Lindzen et al. 2001), and a reduced climate/carbon cycle feedback (Luo et al. 2001). Gray: range of temperature projections from the IPCC Third Assessment Report

'central' scenarios, warming from 1990 to the year 2100 in IS92a drops from 2.6 to $1.5^{\circ} \mathrm{C}$ and TAR scenario A1B declines from 2.9 to $1.7^{\circ} \mathrm{C}$.

\section{ADJUSTMENT FOR OBSERVED TRENDS IN $\mathrm{CO}_{2}$ EMISSIONS}

As an alternative to the $\mathrm{CO}_{2}$ emission pathways as prescribed by the IPCC TAR storylines and the time series of atmospheric $\mathrm{CO}_{2}$ loadings that result (derived from the particular carbon cycle model employed), one could take the observed behavior of the atmospheric $\mathrm{CO}_{2}$ concentrations as a total integrator of technological, biological, and geochemical processes that impact the atmospheric $\mathrm{CO}_{2}$ burden. For most of the history of climate modeling, including a compendium of recent results detailed by Meehl et al. (2000), GCM projections assume a $1 \% \mathrm{yr}^{-1}$ increase in effective $\mathrm{CO}_{2}$ concentration from background conditions. This is clearly not true, as it would produce a doubling in $70 \mathrm{yr}$, while the effective change in $\mathrm{CO}_{2}$ concentration (counting the assumed forcing from all greenhouse emissions, including methane, chlorofluorocarbons, etc.) is usually assumed to be about 50 to $60 \%$ above the preindustrial background (IPCC 2001).

The use of this wrong assumption results in overestimation of future warming. In addition, the non- $\mathrm{CO}_{2}$ greenhouse enhancers are becoming increasingly inconsequential. Radia- tively active chlorofluorocarbons have been effectively banned by the Montreal Protocol and atmospheric concentrations are beginning to decrease (Hansen \& Sato 2001). Methane concentrations have leveled (Dlugokencky et al. 1998). $\mathrm{CO}_{2}$ is the major greenhouse gas that continues to increase. These changes are reflected somewhat in the TAR SRES scenarios, but nevertheless, the majority of the SRES scenarios result in a rate of atmospheric $\mathrm{CO}_{2}$ buildup that greatly exceeds observed trends.

The temporal behavior of the historical series of annual atmospheric $\mathrm{CO}_{2}$ concentration as measured at Mauna Loa (Keeling \& Whorf 2002) from 1958 to 2000 is best fit with a quadratic model including both a linear and a quadratic term. However, when successive years from the start of the record are withheld from the analysis, we find that the quadratic term becomes nonsignificant beginning in 1975 (as indicated by its pvalue in the regression equation). This implies that the non-linear term contains no statistically significant information during the post-1974 time period and that the observed changes in $\mathrm{CO}_{2}$ concentration in the last quarter-century are best fit by a simple linear model with a trend of $1.54 \mathrm{ppm} \mathrm{yr}^{-1}$. Table 1 summarizes the results of the 2-parameter quadratic and 1-parameter linear models for the period 1975-2000. Fig. 3a graphically demonstrates the stabilization in growth rate (ppm $\mathrm{yr}^{-1}$ ) of atmospheric $\mathrm{CO}_{2}$.

This stabilization has occurred despite a continued increase in the annual rate of global $\mathrm{CO}_{2}$ emissions (Fig. 3b; Marland et al. 2002). From 1975 to 1998, global $\mathrm{CO}_{2}$ emissions increased by $42 \%$ yet the growth rate of atmospheric $\mathrm{CO}_{2}$ burden remained steady. The reasons for a constant $\mathrm{CO}_{2}$ growth rate in the face of steadily increasing emissions are not fully understood

Table 1. Regression results from the 2-parameter quadratic and 1-parameter linear models fit to the observed atmospheric $\mathrm{CO}_{2}$ concentration for the period 1975-2000. SC: standardized coefficient

\begin{tabular}{|lrrrrrr|} 
& Count & $\mathrm{R}$ & $\mathrm{R}^{2}$ & $\mathrm{p}$ & $\begin{array}{c}\text { Regression } \\
\mathrm{SS}\end{array}$ & $\begin{array}{c}\text { Residual } \\
\mathrm{SS}\end{array}$ \\
\hline Quadratic & 25 & 0.999 & 0.998 & $<0.0001$ & 3090.78 & 6.185 \\
Linear & 25 & 0.999 & 0.998 & $<0.0001$ & 3090.38 & 6.584 \\
& & & & & \\
Regression & Coeff. & $\mathrm{SE}$ & $\mathrm{SC}$ & $t$ & $\mathrm{p}$ \\
\hline Quadratic & & & & & \\
$\quad$ Intercept & -2574.5 & 121.2 & -2574.5 & -21.24 & $<0.0001$ \\
$\quad$ Linear & 1.47 & 0.06 & 0.95 & 24.03 & $<0.0001$ \\
$\quad$ Quadratic & 0.0027 & 0.002 & 0.047 & 1.19 & 0.2463 \\
Linear & & & & & \\
$\quad$ Intercept & -2714.6 & 29.5 & -2714.6 & -92.02 & $<0.0001$ \\
$\quad$ Linear & 1.54 & 0.015 & 0.999 & 103.9 & $<0.0001$ \\
& & & & & \\
\hline
\end{tabular}




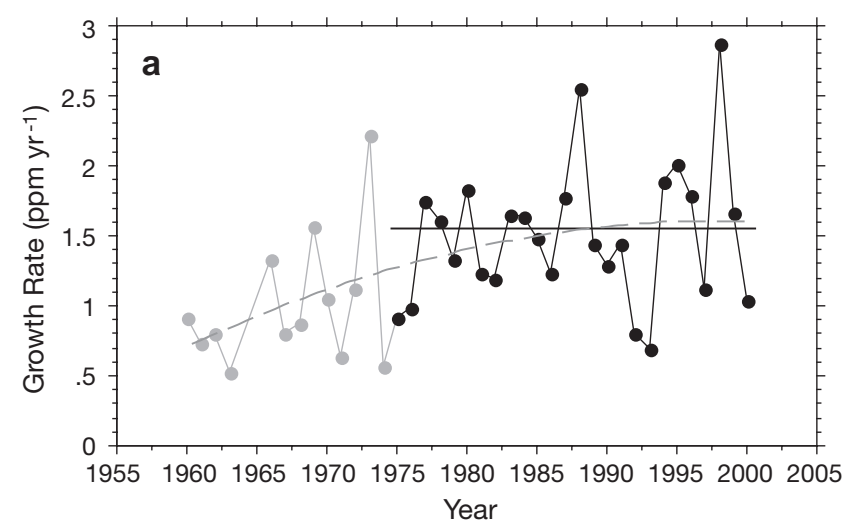

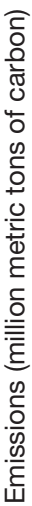

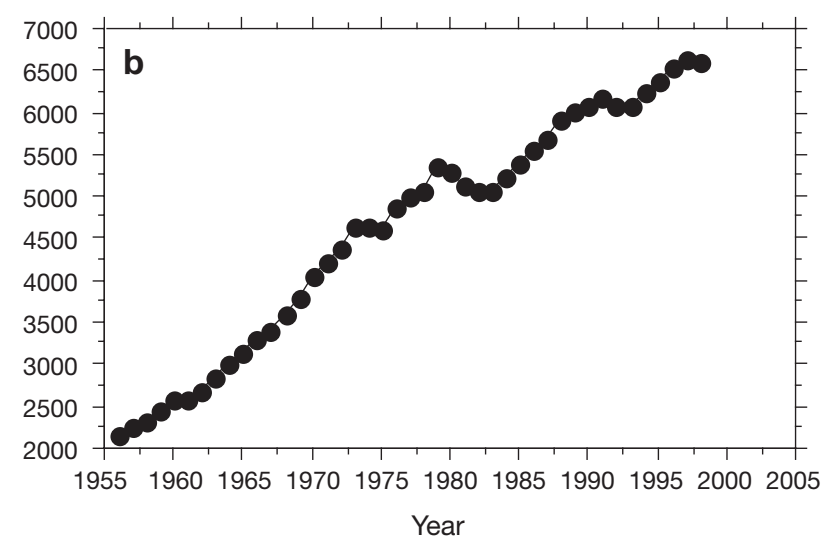

Fig. 3. (a) Annual atmospheric $\mathrm{CO}_{2}$ growth rates (1958-2000); a quadratic fit to the data (gray dotted curve) and a linear fit since 1975 (solid black line) both indicate that the current atmospheric growth rate has levelled off at 1.5 to $1.6 \mathrm{ppm} \mathrm{yr}^{-1}$.

(b) Annual global $\mathrm{CO}_{2}$ emissions (1956-1998)

but require enhanced terrestrial and/or oceanic $\mathrm{CO}_{2}$ uptake. While there exist many carbon cycle models that attempt to explain this behavior, all include varying degrees of uncertainties surrounding every aspect of the models including, but not limited to, the effects of climate interactions, $\mathrm{CO}_{2}$ fertilization, land use alterations, and marine productivity and chemistry changes. The observations, however, include no such uncertainty. They are the perfect integrators of all processes that are currently active. While there have been numerous suggestions that the flat $\mathrm{CO}_{2}$ growth rate of the past 25 yr cannot be maintained (e.g. IPCC 2001, Hansen 2001), there is no indication that the current trend is breaking down. Therefore, an extrapolation of the observed trend should represent a reasonable, if not preferable, scenario of the future $\mathrm{CO}_{2}$ concentrations.

To investigate the effect of a continued linear rise in atmospheric $\mathrm{CO}_{2}$ concentration on projected temperatures, we examined this alternative to the SRES $\mathrm{CO}_{2}$ buildup in the modified MAGICC SAR model. To do this, we developed a $\mathrm{CO}_{2}$ emission scenario that results in an atmospheric growth curve that matches the form of the observations; that is, an extension of the observed linear trend during the past $25 \mathrm{yr}$. By the year 2100 , this produces a $\mathrm{CO}_{2}$ concentration of $522 \mathrm{ppm}$. The range of atmospheric $\mathrm{CO}_{2}$ concentrations that result from the 6 IPCC SRES illustrative scenarios coupled with the variations of the IPCC carbon cycle models is 541 to $970 \mathrm{ppm}$ (Wigley 2000). Each of the 6 SRES illustrative scenarios and 33 of the full set of 35 SRES scenarios creates a greater concentration of atmospheric $\mathrm{CO}_{2}$ than a simple extrapolation of reality does.

We replace the SRES $\mathrm{CO}_{2}$ emissions pathways with the one that is based upon the extrapolation of observations. All other aspects of the SRES scenarios are left unchanged (e.g. $\mathrm{SO}_{2}$ emissions, $\mathrm{CH}_{4}$ emissions, etc.). We then perform 2 sets of MAGICC runs: the first with the adjusted SRES scenarios and the temperature sensitivity fitted to match the TAR results, and the second with the adjustments for $\mathrm{BC}$ and the iris effect. We no longer adjust for the climate/carbon cycle feedback, as we assume that it is implicit in the observed behavior.

Results are presented in Fig. 4, comparing the temperature projections based upon the original SRES scenarios with the ones with a linear $\mathrm{CO}_{2}$ extrapolation from the last quarter-century. In the runs with the fitted SRES temperature sensitivities the range of warming by 2100 is 1.5 to $2.6^{\circ} \mathrm{C}$, a reduction of warming from the IPCC's range of 25 to $42 \%$. The runs with the adjusted temperature sensitivities produced a warming range for 2100 of 1.0 to $1.6^{\circ} \mathrm{C}$, a reduction from the IPCC range of 50 to $64 \%$.

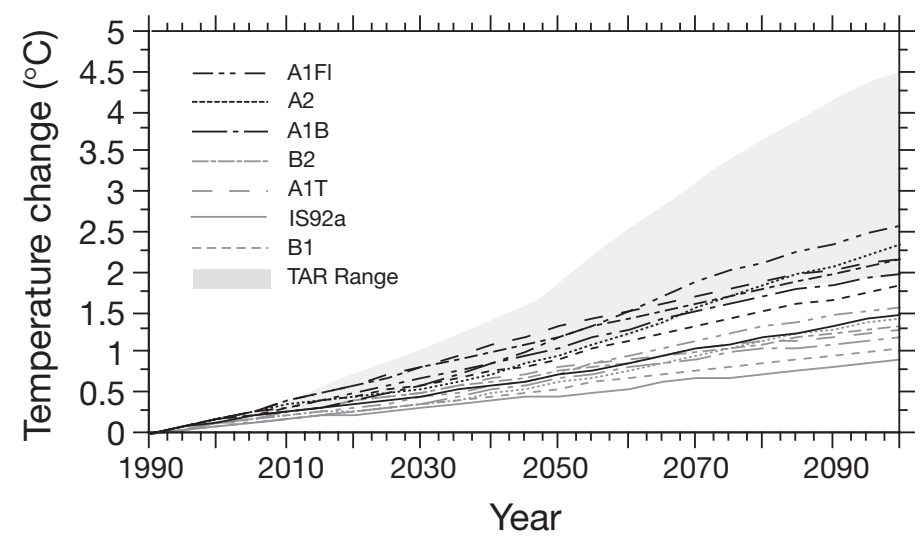

Fig. 4. Temperature projections for the 6 illustrative SRES scenarios and the IS92a scenario adjusted to include a linear extrapolation of observed atmospheric $\mathrm{CO}_{2}$ growth rates. The black curves result from the use of the fit TAR values of temperature sensitivity, while the gray curves result from the use of the adjusted temperature sensitivities. Gray: range of temperature projections from the IPCC Third Assessment Report 


\section{ADJUSTMENT OF MODEL OUTPUT WITH OBSERVED TEMPERATURES}

As shown by the IPCC TAR, the average of a large sample of climate models run with a $1 \% \mathrm{yr}^{-1}$ increase in effective atmospheric $\mathrm{CO}_{2}$ produces an essentially linear (rather than exponential) increase in temperature for the foreseeable future (Meehl et al. 2000). This largely results from the combination of a logarithmic response in temperature to $\mathrm{CO}_{2}$ increases coupled with an assumed exponential growth, all adjusted implicitly for some thermal lag largely found in the ocean. It is noteworthy that the early parts of the Mauna Loa record (1957-1975) are much more strongly exponential than the last quarter-century. As a result, if there is a lag of a quarter-century or more, we should in fact be in a period of linear warming.

The IPCC SAR noted in 1995 that 'the balance of evidence suggests a discernible human influence on global climate,' and the TAR strengthened this statement by saying that 'there is new and stronger evidence that most of the warming observed over the last $50 \mathrm{yr}$ is attributable to human activities.' Balling et al. (1998) and Michaels et al. (2000) demonstrated that the preponderance of warming is in cold, continental winter anticyclones. Calculations by Staley \& Jurica (1970, 1972) on the overlap between $\mathrm{CO}_{2}$ and water vapor imply that greenhouse warming largely would be concentrated in such air masses, and this is also implicit in many GCMs. Our hypothesis does not imply that the findings of Thompson \& Wallace (2001) relating warming to temporal circulation variations are in question. Rather, circulation changes and direct greenhouse warming of surface anticyclones are not at all mutually inconsistent.

Consequently, the notion that greenhouse warming is the largest signal in recent surface temperature histories, coupled with the notion that the average of all GCMs is linear or very nearly so, leads to an obvious adjustment of the various slopes of model warming with the observed warming. This was first published by Michaels \& Balling (2000) using a limited number of models, and subsequently a very similar calculation was published by Allen et al. (2000) based upon the Hadley Centre Model. Both concluded that warming in the next $50 \mathrm{yr}$ is likely to be around $0.75^{\circ} \mathrm{C}$. More recently, in an analysis which relied exclusively on observations, Hansen \& Sato (2001) carefully examined trends in climate forcing agents, noting that the growth rate of greenhouse gas forcing agents has been declining for the past 20 yr. After reviewing the possible reasons for this decline, they state that 'future global warming can be predicted much more accurately than is generally realized' and that 'practical constraints on changes in emission levels suggest that

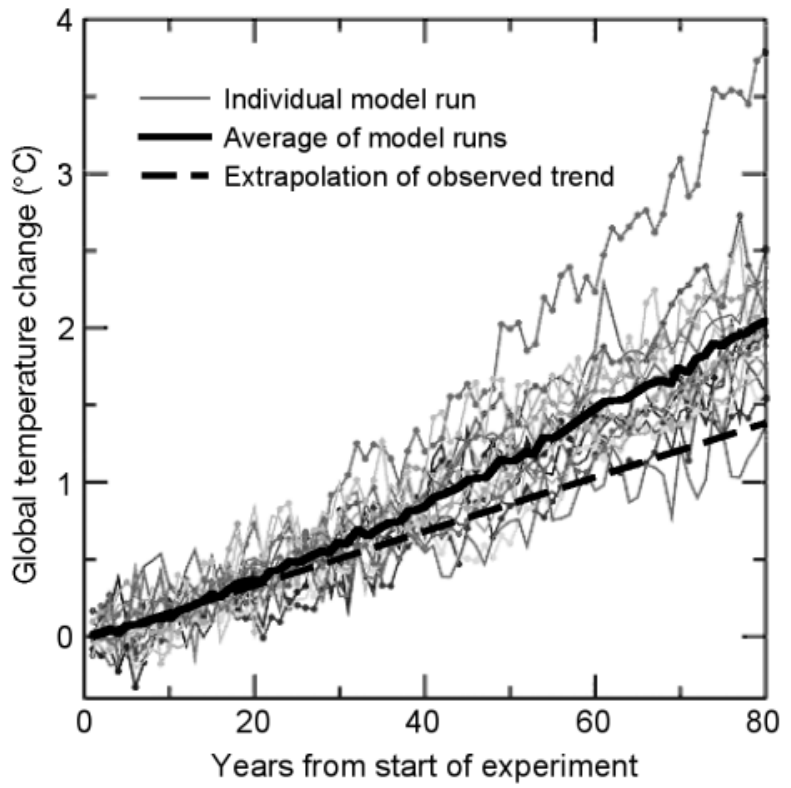

Fig. 5. Extrapolation of the observed temperature trend during the past $25 \mathrm{yr}$ (thick dashed line) plotted with a collection of climate model output run with a $1 \% \mathrm{yr}^{-1}$ effective $\mathrm{CO}_{2}$ increase (thin gray curves). Thick solid line: mean of all models (adapted from IPCC 2001)

global warming at a rate of $+0.15 \pm 0.05^{\circ} \mathrm{C}$ per decade will occur over the next several decades.'

Fig. 5 superimposes the observed warming of the last quarter-century upon IPCC TAR Fig. 9.3a, which includes projections from a large suite of models each run under the simple assumption of a $1 \% \mathrm{yr}^{-1}$ increase of atmospheric $\mathrm{CO}_{2}$. If we project the warming rate of each model in Fig. 5 to encompass 11 decades of exponential $\mathrm{CO}_{2}$ increase (so that it is comparable to the change from 1990-2100), the range of temperature increase is 1.9 to $4.5^{\circ} \mathrm{C}$ with a mean value of $2.75^{\circ} \mathrm{C}$. The extrapolation of the warming trend of $0.17^{\circ} \mathrm{C}$ per decade that is characteristic of the past $25 \mathrm{yr}$ produces a warming from $1990-2100$ of $1.9^{\circ} \mathrm{C}$ or a value that is $68 \%$ of the mean of the individual model projections. Adjusting the high and low extreme model projections by this amount results in a range of 1.3 to $3.0^{\circ} \mathrm{C}$.

\section{DISCUSSION AND CONCLUSIONS}

Our adjustments of the projected temperature trends for the 21st century all produce warming trends that cluster in the lower portion of the IPCC TAR range. Together, they result in a range of warming from 1990 to 2100 of 1.0 to $3.0^{\circ} \mathrm{C}$, with a central value that averages $1.8^{\circ} \mathrm{C}$ across our analyses. These results are from somewhat independent analyses inasmuch as our first set of adjustments is largely a modification of climate 
model input, while the second is an adjustment to climate model output. The first incorporates the observed behavior of the sensitivity (of both temperature and the biosphere), an adjustment for infrared radiation flux, and a simple integration of the planet's response to what the IPCC claims is responsible for 'most of the warming' in the last several decades. The second assumes that climate models have the form of the warming correct but generally overestimate its magnitude.

Our analysis differs from attempts to assign probabilities to future temperature projections in that we explore the effect of recent refinements to the understanding of key climate parameters while other studies (Reilly et al. 2001, Wigley \& Raper 2001) examine the implication of the uncertainty range of climate parameters, a range that is guided by IPCC science rather than the recent refinements thereof, or the actual distribution statistics of the full set of IPCC projections (Schneider 2001).

The parameters that we examine in this study are only a subset of all those which have an impact on the earth's climate. The level of understanding of these parameters and the processes in which they are involved will continue to become more refined with time. In that light, our findings themselves will surely have to be modified as the results of new and ongoing research becomes available. Future results may serve to further reduce the range of expected 21st century temperature changes, or, in fact they may serve to broaden the range.

Despite the uncertainty that future results may hold, the set of climate observations continues to expand and the trends in fundamental quantities such as atmospheric $\mathrm{CO}_{2}$ concentrations and global temperatures are becoming better established. Since these quantities serve as integrators of all processes acting on and within these systems, the only uncertainty they contain is measurement uncertainty, which is arguably small. Therefore, these trends should serve as the de facto standard for future expectations, at least in the near term and should be better incorporated into longer-term projections of future temperature changes.

These trends suggest that even the temperature range and central values determined in our study may be too great. Observations of atmospheric $\mathrm{CO}_{2}$ buildup and global $\mathrm{CO}_{2}$ emissions demonstrate that the family of IPCC 'storylines' that lead to exponential warming, characterized by A1FI in Fig. 1, is not based upon the reality of recent decades. The 'worst case' warming now appears to be merely linear, subject to the modifications described in this paper. Furthermore, both Table 1 and Fig. 3 indicate that any exponential rise in atmospheric $\mathrm{CO}_{2}$ concentrations is weak at best. Con- sequently, the current linear warming may in fact be the adjustment to the exponential growth in $\mathrm{CO}_{2}$ that took place prior to 1975. Levitus et al. (2000) documented a warming of $0.06^{\circ} \mathrm{C}$ in the top $3 \mathrm{~km}$ of a largearea ocean sample over the course of $40 \mathrm{yr}$. A lag correlation between that deep-water record and the sea-surface temperature record from Quayle et al. (1999) is very suggestive that oceanic thermal lag maximizes around $35 \mathrm{yr}$ (Michaels et al. 2001). Thus, the truly exponential phase of concentration growth in the atmosphere, which ended about 25 yr ago, should induce a linear warming for the next decade or two before it could actually begin to damp. Therefore, if the impact of the mid-century exponential $\mathrm{CO}_{2}$ rise has nearly worked its way through the oceanic thermal lag, our warming projections derived from the assumption of a continued linear buildup of the atmospheric $\mathrm{CO}_{2}$ burden should appear as the upper end of the likely range of warming during this century.

\section{LITERATURE CITED}

Allen M, Stott PA, Mitchell JFB, Schnur R, Delworth TL (2000) Quantifying the uncertainty in forecasts of anthropogenic climate change. Nature 407:617-620

Balling PC, Michaels PJ, Knappenberger PC (1998) Analysis of winter and summer warming rates in gridded temperature timeseries. Clim Res 9:175-181

Bell TL, Chou MD, Hou AY, Lindzen RS (2002) Reply to 'Comments on "Does the earth have an adaptive infrared iris?"' Bull Am Meteorol Soc 83:598-600

Chen J, Carlson BE, Del Genio AD (2002) Evidence for strengthening of the tropical general circulation in the 1990s. Science 295:838-841

Chou MD, Lindzen RS (2002) Comments on 'Tropical convection and the energy balance of the top of the atmosphere.' J Clim 15:2566-2570

Chou MD, Lindzen RS, Hou AY (2002a) Comments on 'The iris hypothesis: a negative or positive cloud feedback?' J Clim 15:2713-2715

Chou MD, Lindzen RS, Hou AY (2002b) Impact of albedo contrast between cirrus and boundary-layer clouds on climate sensitivity. Atmos Chem Phys (in press)

Chou MD, Lindzen RS, Hou AY (2002c) Reply to 'Tropical cirrus and water vapor: an effective Earth infrared iris feedback?' Atmos Chem Phys 2:99-101

Cox PM, Betts RA, Jones CD, Spall SA, Totterdell IJ (2000) Acceleration of global warming due to carbon-cycle feedbacks in a coupled climate model. Nature 408:184-187

Dlugokencky EJ, Masarie KA, Lang PM, Tans PP (1998) Continuing decline in the growth rate of the atmospheric methane burden. Nature 393:447-450

Fu Q, Baker M, Hartmann DL (2001) Tropical cirrus and water vapor: an effective earth infrared iris? Atmos Chem Phys Discuss 1:221-238

Fu Q, Baker M, Hartmann DL (2002) Tropical cirrus and water vapor: an effective earth infrared iris? Atmos Chem Phys 2:31-37

Gaffen DJ, Santer BD, Boyle JS, Christy JR, Graham, Ross RJ (2000) Multidecadal changes in the vertical temperature structure of the tropical troposphere. Science 287: $1242-1245$ 
Hansen JE, Sato M (2001) Trends of measured climate forcing agents. Proc Natl Acad Sci USA 98:14778-14783

Harrison H (2002) Comments on 'Does the earth have an adaptive infrared iris?' Bull Am Meteorol Soc 83:597

Hartmann DL, Michelsen ML (2002) No evidence for iris. Bull Am Meteorol Soc 83:249-254

Harvey LDD (2000) An assessment of the potential impact of a downward shift of tropospheric water vapor on climate sensitivity. Clim Dyn 16:491-500

Hegerl GC, Wallace JM (2002) Influence of patterns of climate variability on the difference between satellite and surface temperature trends. J Clim 15:2412-2428

IPCC (1996) Climate change 1995: the science of climate change. Contribution of Working Group I. In: Houghton JT, Meira Filho LG, Callander BA, Harris N, Kattenberg A, Maskell K (eds) Second Assessment Report of the Intergovernmental Panel on Climate Change. Cambridge University Press, Cambridge

IPCC (2001) Climate Change 2001: the scientific basis. Contribution of Working Group I. In: Houghton JT, Ding Y, Griggs DJ, Moguer M, van der Linden PJ, Dai X, Maskell K, Johnson CA (eds) Third Assessment Report of the Intergovernmental Panel on Climate Change. Cambridge University Press, Cambridge

IPCC (2000) Special report on emissions scenarios. In: Nakicenovic N, Alcamo J, Davis G, de Vries B and 24 others (eds) A special report of Working Group III of the Intergovernmental Panel on Climate Change. Cambridge University Press, Cambridge

Jacobson MZ (2001) Strong radiative heating due to the mixing state of black carbon in atmospheric aerosols. Nature 409:695-697

Keeling CD, Whorf TP (2002) Atmospheric $\mathrm{CO}_{2}$ records from sites in the SIO air sampling network. In: Carbon Dioxide Information Analysis Center. Trends online: a compendium of data on global change. Oak Ridge National Laboratory, US Department of Energy, Oak Ridge, TN (cdiac.esd.ornl.gov/trends/co2/sio-mlo.htm)

Levitus S, Antonov JI, Boyer TP, Stephens C (2000) Warming of the world ocean. Science 287:2225-2229

Lin B, Wielicki BA, Chambers LH, Hu Y, Xu K (2002) The iris hypothesis: a negative or positive cloud feedback? J Clim 15:3-7

Lindzen RS, Chou MD, Hou AY (2001) Does the earth have an adaptive infrared iris? Bull Am Meteorol Soc 82:417-432

Lindzen RS, Chou MD, Hou AY (2002) Response to 'No evidence for iris.' Bull Am Meteorol Soc 83: 1345-1348

Liski J, Ilvesniemi H, Mäkelä A, Westman CJ (1999) $\mathrm{CO}_{2}$ emissions from soil in response to climate warming are overestimated-The decomposition of old soil organic matter is tolerant of temperature. Ambio 28:171-174

Luo Y, Wan S, Hui D, Wallace LL (2001) Acclimatization of soil respiration to warming in a tall grass prairie. Nature 413: $622-625$

Marland G, Boden T, Andres RJ (2002) Global $\mathrm{CO}_{2}$ emissions from fossil-fuel burning, cement manufacture, and gas flaring: 1751-1998. In: Carbon Dioxide Information Analysis Center. Trends online: a compendium of data on global

Editorial responsibility: Chris de Freitas,

Auckland, New Zealand change. Oak Ridge National Laboratory, US Department of Energy, Oak Ridge, TN (cdiac.esd.ornl.gov/trends/ emis/meth_reg.htm)

Meehl GA, Boer GJ, Covey C, Latif M, Stouffer RJ (2000) The coupled model intercomparison project (CMIP). Bull Am Meteorol Soc 81:313-318

Michaels PJ, Balling RC (2000) The satanic gases: clearing the air about global warming. Cato Institute, Washington, DC

Michaels PJ, Knappenberger PC, Balling RC, Davis RE (2000) Observed warming in cold anticyclones. Clim Res 14:1-6

Michaels PJ, Knappenberger PC, Davis RE (2001) Integrated projections of future warming based upon observed climate during the attenuating greenhouse enhancement. In: Chylek P, Lesins G (eds) Proc 1st Int Conf Global Warming and Next Ice Age. Dalhousie University, Halifax, p 162-167

Quayle RG, Peterson TC, Basist AN, Godfrey CS (1999) An operational near-real-time global temperature index. Geophys Res Lett 26:333-335

Raper SCB, Wigley TML, Warrick RA (1996) Global sea-level rise: past and future. In: Milliman JD, Haq BU (eds) Sea level rise and coastal subsidence: causes, consequences and strategies. Kluwer Academic, Dordrecht, p 11-45

Raper SCB, Gregory JM, Osborn TJ (2001) Use of an upwelling-diffusion energy balance climate model to simulate and diagnose A/OGCM results. Clim Dyn 17: 601-613

Reilly J, Stone PH, Forest CE, Webster MD, Jacoby HD, Prinn RG (2002) Uncertainty and climate change assessments. Science 293:430

Schneider SH (2001) What is 'dangerous' climate change? Nature 411:17-19

Staley DO, Jurica GM (1970) Flux emissivity tables for water vapor, carbon dioxide and ozone. J Appl Meteorol 9: $365-372$

Staley DO, Jurica GM (1972) Effective atmospheric emissivity under clear skies. J Appl Meteorol 11:349-356

Thompson DWJ, Wallace JM (2001) Regional climate impacts of the Northern Hemisphere Annular Mode. Science 293: $85-89$

Verville JH, Hobbie SE, Chapin FS, Hooper DU (1998) Response of tundra $\mathrm{CH}_{4}$ and $\mathrm{CO}_{2}$ flux to manipulation of temperature and vegetation. Biogeochemistry 41: 215-235

Wang PH, Minnis P, Wielicki BA, Wong T, Vann LB (2002) Satellite observations of long-term changes in tropical cloud and outgoing longwave radiation from 1985 to 1998. Geophys Res Lett 29: No. 10, 10.1029/2001GL014264

Wielicki BA, Wong T, Allan RP, Slingo A and 9 others (2002) Evidence for large decadal variability in the tropical mean radiative energy budget. Science 295:841-844

Wigley TML (2000) Updated version of and results from the simple climate model MAGICC. www.acacia.ucar.edu

Wigley TML, Raper SCB (1987) Thermal expansion of sea water associated with global warming? Nature 349: 503-506

Wigley TML, Raper SCB (2002) Interpretation of high projections for global-mean warming. Science 293:451-454

Submitted: May 17, 2002; Accepted: September 2, 2002

Proofs received from author(s): October 16, 2002 